\title{
Canine Filariasis Outbreak in Southwestern Colombia: A Molecular and Epidemiological Study
}

\author{
Nathaly Espinosa ${ }^{1}$, Angelo Rosero ${ }^{1}$, Claudia Lucia Villegas ${ }^{2}$, Isabel Cristina Garcia ${ }^{2}$, Tania \\ Gaviria-Cantinn', Alejandra Peña N", Beatriz E. Ferro', Luisa Maria Nieto Ramirez ${ }^{{ }^{*}}$ \\ 1 Facultad de Ciencias Básicas. Universidad Santiago de Cali, Santiago de Cali, Colombia \\ 2 Laboratorio Clínico Veterinario Zoolavet, Santiago de Cali, Colombia \\ 3 Bacterial Cell cycle \& Development (BCcD), Biology of Microorganisms Research Unit (URBM). University \\ of Namur, Belgium \\ 4 Departamento Administrativo de Planeación Municipal, Santiago de Cali, Colombia \\ 5 Facultad de Ciencias de la Salud. Universidad Icesi, Santiago de Cali, Colombia \\ * Correspondence: nieto.luisa@gmail.com; +57-(2)-518-3000 Ext 389
}

\begin{abstract}
Different nematodes affect canines, however, Dirofilaria immitis is the most prevalent filariae. D. immitis causes heartworm disease that can be fatal for dogs and potentially transmitted to humans. Climate change, animal migration, among other factors have changed the dynamics of vector-borne diseases, including filariasis. In the last four years, a sudden increase of dogs with microfilaremia was reported by different veterinary centers in Cali, the main city of Southwest Colombia. The objective of this study was to molecularly identify the etiologic agent of this filariasis outbreak reported in this area from 2018-2019, using a novel PCR-RFLP method. Those filariasis cases were initially detected by microscopic and serological tests. A total of 82 canine filariasis cases were molecularly analyzed, identifying $55(67 \%)$ of them as Acantacheilonema reconditum. PCR-sequencing was performed in eight cases confirming this finding. The filariasis cases were statistically associated with male dogs who had clinical signs of anemia, with low levels of hemoglobin and hematocrit ( $p<0.0001)$, and high levels of plasma proteins ( $p<0.001)$. This emerging canine disease constitutes an important public health concern among clinicians and advises active surveillance to explore its zoonotic potential.
\end{abstract}

Keywords: Dogs, Microfilariae, Acanthocheilonema, PCR-RFLP, Cali, Zoonosis

\section{Introduction}

Filariasis is a parasitic disease caused by nematodes of the Onchocercidae family that affect a wide variety of mammals. Microfilariae is the first larval stage of the nematode that can be observed circulating in peripheral blood, representing the parasite diagnostic stage [1, 2]. Among these parasites, Dirofilaria immitis is the most widely known since it causes heartworm disease in canines. This disease can be fatal and is distributed particularly in the "new world" $[1,3]$. Another known filaria species is D. repens that is observed particularly in European countries. These two Dirofilaria species do not show specificity for their host, infecting domestic and wild dogs and to a less extent humans and cats $[1,4,5]$. Acanthocheilonema reconditum is also a filaria that affects canines, that similar to D. repens, can be found subcutaneously, causing from no clinical signs to skin and soft tissue-related pathologies [6].

Canine filariasis caused by D. immitis has been detected in South America since 1875. Countries such as Brazil, Argentina, and Peru have reported this disease with different frequencies (from 3.5 up to $23.5 \%$ ) in the last two decades [7, 8]. The distribution of filariasis in Colombia has been mainly determined using serological tests to detect $D$. immitis antigens in most of the 
geographic regions of this country, varying from less than $0.5 \%$ in the Andean region to about $20 \%$ in the Caribbean region during the last 18 years [8-12]. In the Southwest of Colombia, there are not recent studies about the distribution of filarial nematodes among dogs. The last study reported in 1967 showed a prevalence of $5 \%$ for D. immitis in canines from the city with the largest metropolitan area of Southwest Colombia: Cali $[2,13]$.

The transmission of filaria infection in dogs is influenced by the causing parasitic species as well as external environmental factors [14]. Depending on the nematode's species, different arthropods have been identified as biological vectors, generating different transmission dynamics. For instance, D. immitis is transmitted by mosquitoes such as Aedes spp, Culex spp, and Anopheles spp [1]; while A. reconditum is transmitted by fleas such as Ctenocephalides felis, C. canis, and lice such as Heterodoxus spiniger [3]. Besides, climate change, constant human and animal migration and commercial trades have a direct effect on the incidence, distribution, and control of endemic and emerging vector-borne diseases [8, 15-18]. These events impose the need for constant surveillance of canine filariasis, as a vector-borne disease with zoonotic potential [1, 19]. Veterinary diagnostic centers of Cali, Colombia, recently reported an unusual increase in the number of microfilariasis in dogs since 2016 compared with previous years (unpublished data), suggesting a canine filariasis outbreak in the Southwestern region of this country. Interestingly, most cases (detected by microscopy) were negative for commercial serologic tests for $D$. immitis, generating some concerns about the etiology of the increasing filaria cases observed in Cali. The latter emphasizes the need for novel diagnostic approaches to specifically identify the filarial species involved in this outbreak to establish directed and more efficient therapeutic options and control measures. For this reason, here we conducted a prospective study that aims to propose a novel molecular method to identify the circulating filariae in canines from Southwest Colombia and epidemiologically characterize the cases registered for one year.

\section{Results}

\subsection{Microscopic and Serologic test}

From August 2018 to August 2019, 2,971 blood samples from different canines were analyzed for the presence of hemoparasites. A total of $102(3.4 \%)$ patients were identified with microfilariae by microscopic examination (Figure 1), but only 82 met the inclusion criteria. Out of the 82 filaria cases, only three were positive for the D. immitis antigen. Moreover, 43 healthy individuals were included as controls with negative results for both microscopic and serologic tests.

\subsection{Demographic Data Analysis}

The median age for both cases and controls was 5 years, with an interquartile range (IQR) of 2-9 years for filaria cases and 3-8 years for controls. Most of the cases were male (64/82), having filariasis significantly associated with male sex $(p<0.00001$, Table 1$)$. Regarding the breed, the mestizo/mixed predominated among cases and controls, followed by the Poodle and Schnauzer (Table 1). 


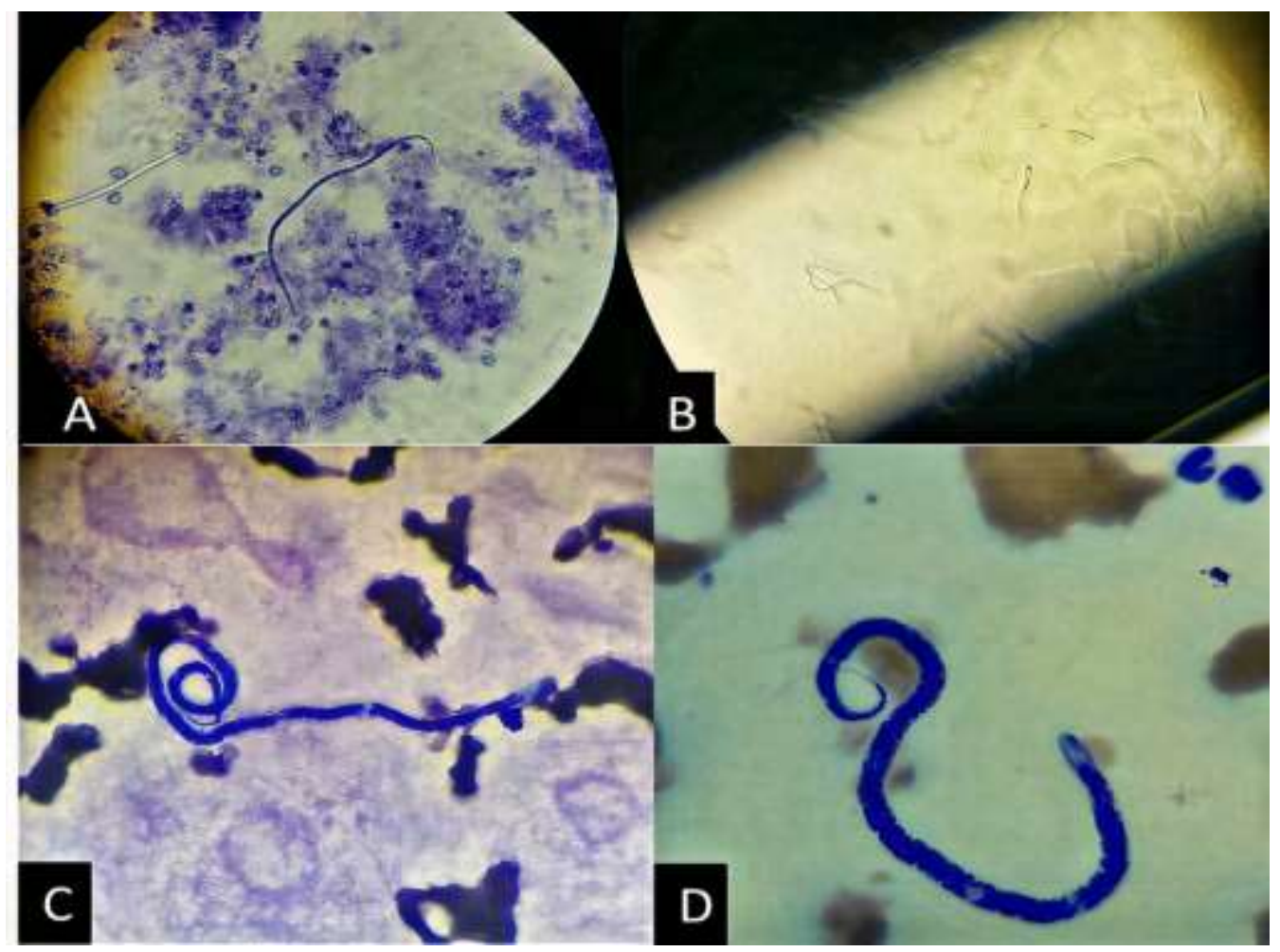

Figure 1. Microscopic detection of microfilariae in dogs from Southwestern Colombia. A. Knott's test. B. Direct observation in the microhematocrit tube. C. and D. Blood samples stained with Wright showing the microfilaria.

Table 1. Demographic characteristics of the analyzed dogs.

\begin{tabular}{ccccc}
\hline Variable & Cases & Controls & p-value $^{1}$ & OR (CI 95\%) \\
\hline Age groups (years) & $\mathrm{n}(\%)$ & $\mathrm{n}(\%)$ & 0.352 & $1.3(0.7-2.4)$ \\
$<2$ & $13(62)$ & $8(38)$ & & \\
$2-8$ & $49(64)$ & $28(36)$ & & \\
$\geq 9$ & $20(74)$ & $7(26)$ & & \\
Sex & & & & \\
Male & $64(84.2)$ & $12(15.8)$ & & \\
Female & $18(36.7)$ & $31(63.3)$ & & \\
Dog's breed & & & \\
Mestizo/Mixed & $48(68)$ & $23(32)$ & & \\
Poodle & $8(100)$ & $0.4(0)$ & & \\
Schnauzer & $7(54)$ & $6(46)$ & & \\
Labrador retriever & $5(71)$ & $2(29)$ & \\
Miniature Pinscher & $3(60)$ & $2(40)$ & \\
Others & $11(52)$ & $10(48)$ & \\
\hline
\end{tabular}

1. Bivariate analysis 
Hematocrit and hemoglobin were significantly reduced in filaria cases compared to controls $(p<0.0001)$. Furthermore, a significant increase in the plasmatic protein levels was found for cases with a median of $79 \mathrm{~g} / \mathrm{L}$, which is above the reference values $(60-75 \mathrm{~g} / \mathrm{L})$. On the other hand, there was not a significant difference for the eosinophil count, or any other blood cell population count between filaria cases and controls (Table 2).

Regarding clinical characteristics, infected dogs had clinical signs of anemia (such as weakness, 12/82, 14.6\%), followed by skin problems (6/82, 7.3\%), bleeding (including ulcers and eye bleeding, 6/82, 7.3\%), malnutrition and cachexia (5/82, 6.1\%), and respiratory distress (5/82, $6.1 \%)$. However, most filaria cases did not reveal relevant signs of disease (40/82, 48.8\%). Interestingly, about 39\% (32/82) of owners reported their dogs having infestation with one or more types of ectoparasites (fleas, ticks, or lice).

Table 2. Comparison of hemogram results between filaria cases and controls.

\begin{tabular}{|c|c|c|c|c|c|}
\hline Variable & Units & $\begin{array}{l}\text { Reference } \\
\text { values }^{1}\end{array}$ & $\begin{array}{c}\text { Cases } \\
\text { (median) }\end{array}$ & $\begin{array}{l}\text { Controls } \\
\text { (median) }\end{array}$ & $p$-value ${ }^{2}$ \\
\hline Hemoglobin & $g / d L$ & $12-18$ & 12.9 & 17.0 & $<0.0001$ \\
\hline Hematocrit & $\%$ & $37-55$ & 37.0 & 49.9 & $<0.0001^{3}$ \\
\hline Leukocytes & $\times 10^{3}$ cells $/ \mathrm{mm}^{3}$ & $6.0-17.0$ & 10.8 & 10.6 & 0.84 \\
\hline Neutrophils & $\times 10^{3}$ cells $/ \mathrm{mm}^{3}$ & $3-12$ & 6.5 & 6.3 & 0.55 \\
\hline Lymphocytes & $\times 10^{3}$ cells $/ \mathrm{mm}^{3}$ & $1.0-4.8$ & 2.2 & 2.5 & 0.60 \\
\hline Eosinophils & $x 10^{3}$ cells $/ \mathrm{mm}^{3}$ & $0.1-0.9$ & 0.38 & 0.43 & 0.50 \\
\hline $\begin{array}{l}\text { Total plasmatic } \\
\text { proteins }\end{array}$ & $g / L$ & $60-78$ & 79 & 70 & 0.0015 \\
\hline
\end{tabular}

1. According to the clinical laboratory and also established elsewhere [20, 21]

2. Comparison using Mann-Whitney test

3. Non-parametric unpaired t test with Welch correction

\section{4. "Pan-filarial" PCR and RFLP analysis}

Out of the 82 microscopically identified filaria cases, $81.7 \%$ (67/82) resulted positive for the PCR pan-filarial test (Figure 2). Additionally, the pan-filarial PCR was performed for the 43 controls, all of which were negative. RFLP analysis of the "pan-filarial" PCR product allowed the molecular identification of $55 \mathrm{~A}$. reconditum cases among the 67 pan-filarial PCR positive cases (Figure 3). The positivity was determined by the presence of one band of $288 \mathrm{bp}$ approximately in the agarose gel, representing two DNA fragments of 285 and 288 base pairs (bp).

\subsection{PCR-Sequencing and serological testing}

Only three cases (cases No. 30, 46, 67) had positive results for the D. immitis antigen test. However, all these cases had been identified as A. reconditum by PCR-RFLP. PCR-sequencing of these three cases confirmed our PCR-RFLP results (Table 4). Additionally, five additional cases (from No. 01 to 05 ) were PCR-sequenced, confirming the presence of $A$. reconditum in our sample set and the PCR-RFLP results. With the PCR-sequenced cases $(\mathrm{n}=8)$, an NJ phylogenetic analysis was performed, identifying four unique species and two clusters for the A. reconditum species (Table 4). 


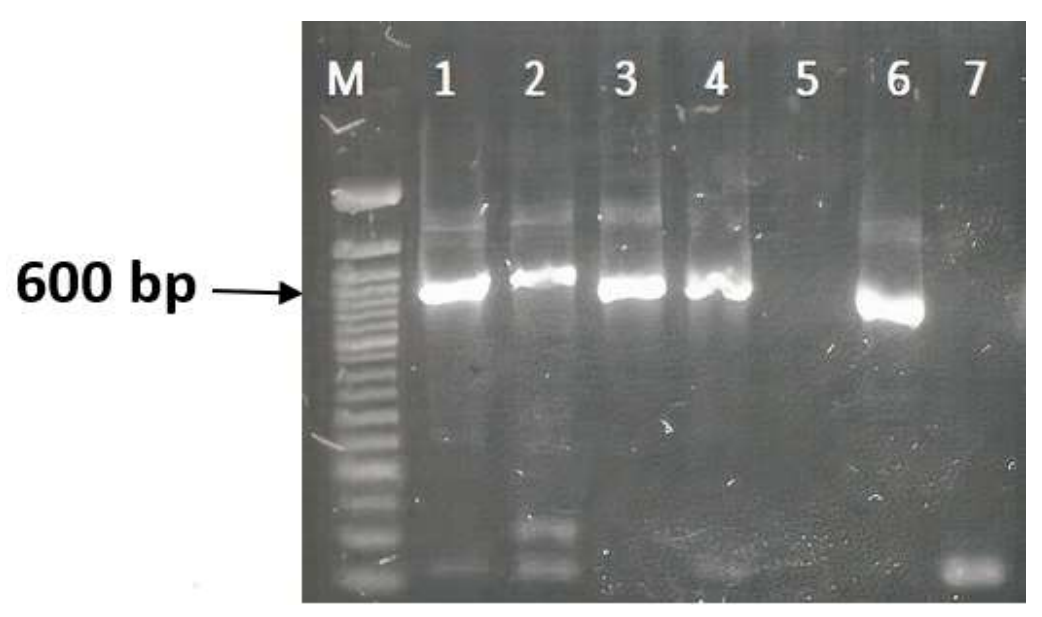

Figure 2. Electrophoresis of pan-filarial PCR for canine filariasis identified and one control in 1.5\% agarose gel. M: Ladder. Lanes 1-4: cases 1 , 2, 3, and 7. Lane 5: control 1. Lane 6: positive control (A. reconditum DNA). Lane 7: Negative Control.

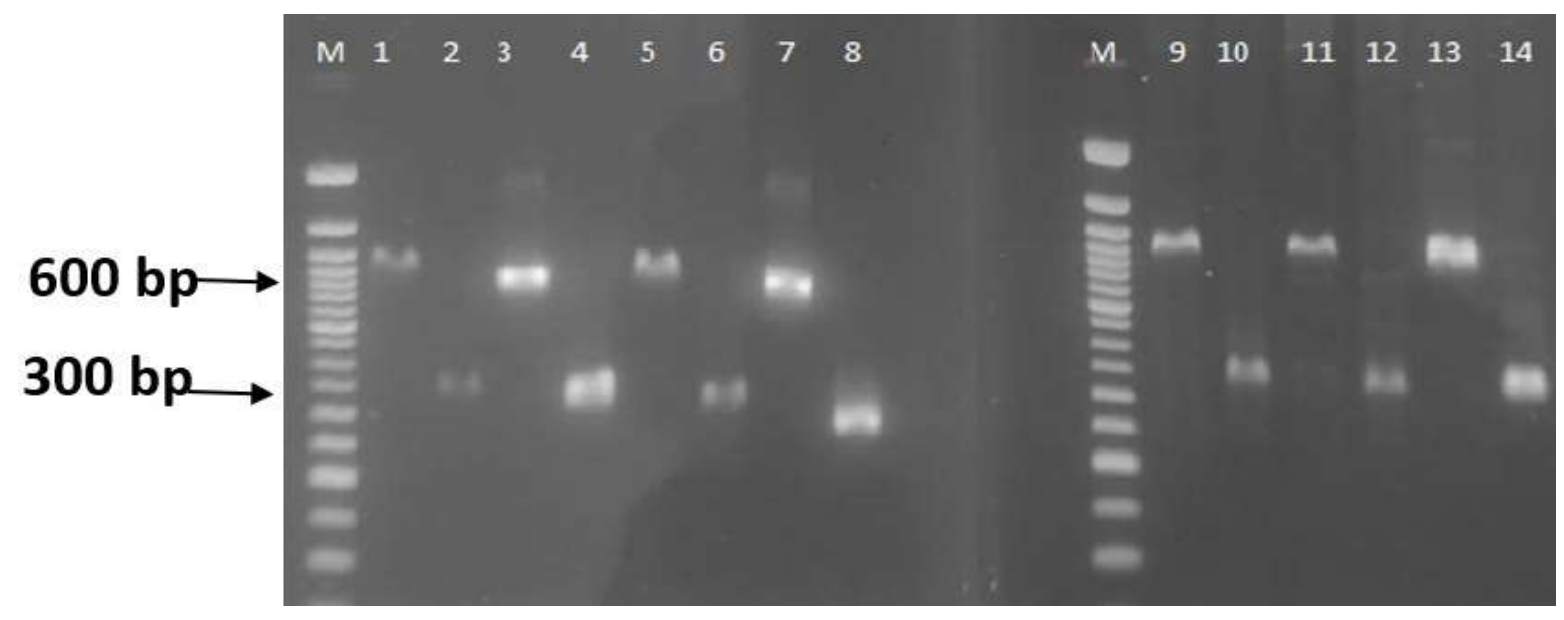

Figure 3. Electrophoresis of pan-filarial PCR product for cases and its respective $M w o I$ digestion in 1.5\% agarose gel. M. Ladder. Lanes 1 and 2: A. reconditum (positive control) and digested product. Lanes 3 and 4: case 94 and digested product. Lanes 5 and 6: case 95 and digested product. Lanes 7 and 8: case 96 and digested product. M: Ladder. Lanes 9 and 10: case 57 and digested product. Lanes 11 and 12: case 58 and digested product. Lanes 13 and 14: case 59 and digested product.

Table 3. Molecular test results for cases and controls

\begin{tabular}{|c|c|c|}
\hline Molecular test & Cases & Controls \\
\hline & $\mathrm{N}=82$ & $\mathrm{~N}=43$ \\
\hline Panfilarial PCR & n $(\%)$ & $\mathrm{n}(\%)$ \\
\hline Positive & $67(81.7)$ & $0(0)$ \\
\hline Negative & $15(18.3)$ & $43(100)$ \\
\hline PCR-RFLP & $\mathrm{N}=67$ & \\
\hline Positive for A. reconditum & $55(82.1)$ & ND \\
\hline Negative for $A$. reconditum & $12(17.9)$ & ND \\
\hline
\end{tabular}

ND: not determined 
Table 4. PCR-sequencing results from the ribosomal DNA interspacer region (5.8S-ITS2-28S).

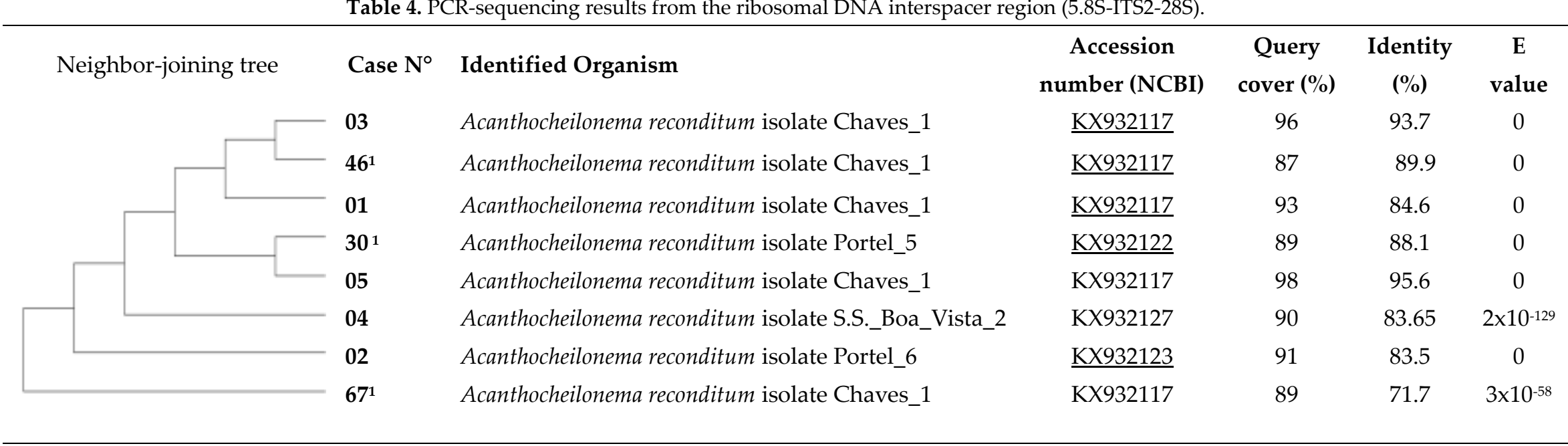

2 1. Discrepant cases between serological and PCR-RFLP test 


\subsection{Geographic distribution of filaria cases}

Most of the filariasis cases were distributed in the urban area of Cali (represented as red dotted lines in Figure 4), specifically, in Southwestern neighborhoods (34/82, 41.5\%). On the other hand, around $13.4 \%(11 / 82)$ of the filariasis cases were from other cities of the state of Valle del Cauca, such as Restrepo, Dagua, Yumbo, and Jamundí. Additionally, five cases (6.1\%) were identified from Northern cities of the neighboring state of Cauca, such as Santander de Quilichao and Caloto, among others (Figure 4).

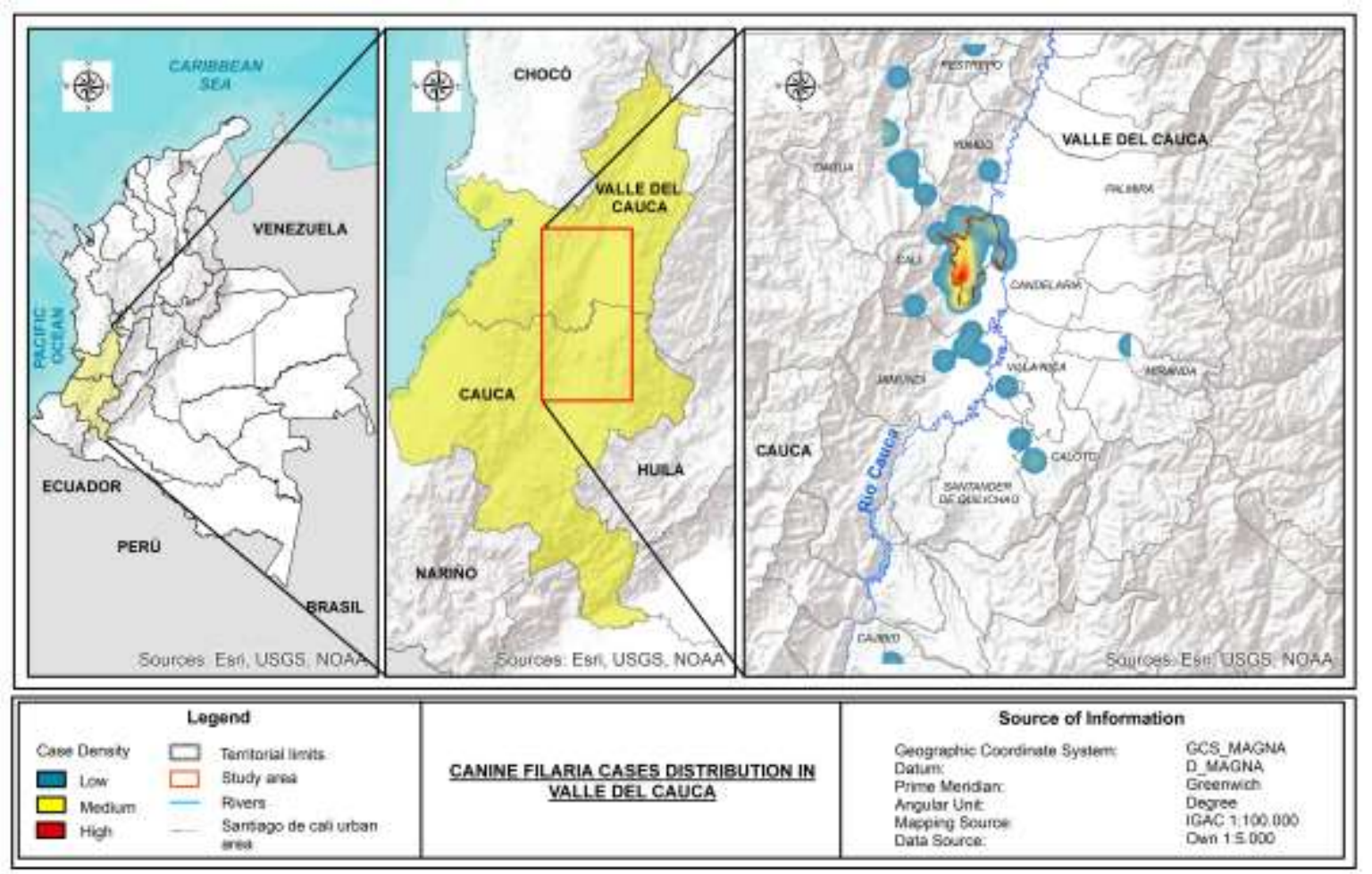

Figure 4. Geographical distribution of the canine filaria cases detected in Southwest Colombia. ESRI: Environmental Systems Research Institute, USGS: United States Geological Survey, NOOA: National Oceanic and Atmospheric Administration.

\section{Discussion}

The presence of microfilariae in dogs from Southwestern Colombia was investigated for one year; detecting 102 positive cases by microscopic tests, 82 of them further analyzed by molecular tests. This unusual number of canine filariasis detected in Cali and close cities, represents an outbreak since less than 16 cases per year were reported between 1999 - 2003 in Cali (unpublished local data). It is important to mention that canine filariasis are not part of current public health surveillance in Colombia. In fact, since 2013, Colombia was officially declared free of the human filariasis caused by Onchocerca volvulus that affected mostly the Pacific region of the country (the Southwest of Colombia) [22].

Our study is a pioneer in Colombia, evaluating this parasitic disease by both conventional and molecular methods (an in-house adapted PCR-RFLP test). Although A. reconditum (previously known as Dipetalonema reconditum) has a worldwide distribution [5, 23-35], the high frequency of this species in Southwestern Colombia is unprecedented, since D. immitis has been the most frequently reported filaria species among canines from Colombia and South America [2, 8, 9, 11, 12]. It is 
important to highlight that a recent study in Brazil also identified a higher distribution of $A$. reconditum over D. immitis (7.2\% versus $2.2 \%$ in 418 samples tested) [32]. This suggests a potential influx of infected animals and/or vectors to Colombia from Brazil or a common source for both South American countries, that could represent a public health concern in the context of a zoonotic disease in a globalized world. Additionally, this finding rises concerns regarding the distribution of nematodes species and potentially other vector-borne pathogens that can reach human beings and other animal species.

Interestingly, the sequencing results showed a high identity and coverage of the eight analyzed strains with the nematode strains reported from the East of Brazil (Table 4). Five out of the eight sequenced samples had a high similarity ( $\geq 87 \%$ coverage) to the strain KX932117 that was identified in the municipality of Chaves in the state of Pará, Brazil, according to the data submitted to the National Center for Biotechnology Information (NCBI) (Table 4).

In relation to the pan-filarial PCR test, about $82 \%$ of dogs resulted positive and $82.1 \%$ of those were confirmed to be infected with A. reconditum by RFLP. It is important to note that although $18 \%(15 / 82)$ of cases were positive by the microscopic test, they all had negative results by PCR test, possibly attributed to the low parasitemia at the sampling time. This low parasitemia could be explained by two factors: first, the circadian rhythm of the parasite [36], affecting the parasite's DNA content in the dog's bloodstream, or second, by the intake of non-reported medication between the initial diagnosis stage and the time of sampling for DNA isolation. It is important to note that once the dog was positive by the microscopic test, the owner was invited to bring his/her dog for the molecular study and epidemiological characterization. Therefore, the sample was not taken at the same time for both microscopic and molecular tests.

We detected a discrepancy between the serological and PCR-RFLP tests for three cases (cases No. 30, 46, and 67), that could be solved by the PCR-sequencing analysis. As observed in Table 4, case No. 46 is closely related to case No. 03, with high identity with A. reconditum. Cases No. 30 and 67 were also confirmed as $A$. reconditum (Table 4). Although the antigen test applied in the study has a sensitivity of $94 \%$ and specificity of $100 \%$ (according to the manufacturer), these discrepant results may possibly be due to cross-reactivity with $A$. reconditum antigens. Cross-reactivity between $D$. immitis and Acantacheilonema species such as $A$. reconditum and A. odendhali have been previously described [36, 37]. Shared epitopes have been reported even between D. immitis and other nematodes species such as Toxocara canis and Angiostrongylus vasorum [36, 38-40]

A. reconditum is known for its low pathogenicity in canines and association with mild clinical manifestations mainly at the subcutaneous tissue and skin [6,41]. Although, most of the analyzed cases reported here did not have clinical signs of disease, they exhibited a significantly reduced level of hemoglobin and hematocrit compared to controls (Table 2). This finding highlights anemia as an important clinical manifestation of filariasis, most likely caused by A. reconditum (confirmed for $67 \%$ of cases). Additionally, the high levels of plasmatic proteins in canine filariasis suggested an inflammatory response in these dogs. A reduction in hemoglobin concentration and an increase in total protein levels have been previously reported among A. reconditum cases, attributing those findings to the destruction of erythrocytes and the increase of antibody response to parasitic antigens [42]. This high protein levels could be further evaluated in order to find a potential biological marker specific for $A$. reconditum, looking at either host or parasite's proteins. 
Interestingly, $84.2 \%$ of the males that were evaluated in this study were positive cases for canine filariasis (64/76). In fact, our study found that the risk of acquiring microfilaria infection is nine times higher in males than females $(\mathrm{p}<0.00001$, Table 1 ). Two previous studies carried out in Colombia did not find a significant relationship between male dogs and microfilariae infection [9]. In the same sense, a study done in Brazil between 2015 and 2017 reported a higher prevalence of $A$. reconditum in males, albeit without significant differences in relation to the sex of the canine [43]. However, a study carried out in Vesuvius, Italy, in 2000 was in line with our findings, showing that male dogs have a significantly higher risk for $A$. reconditum infection [44]. In the same sense, previous a study attributed a higher prevalence of A. reconditum in male canines (85.7\%) possible to hormonal effects [42].

We did not observe an association of the filaria cases with the age or breed of the dogs. However, a higher proportion of young adult mestizo canines was observed among filariasis cases (Table 1). Few articles referred to the relationship between age and microfilariae infection, for instance, there was a report from Barcelona that showed a significant association of $D$. immitis with dogs older than 5 years [45]. Similarly, a significant relationship between A. reconditum with adult canines was also reported in dogs infected with A. reconditum [44]. Therefore, age should be considered when suspecting filariasis, as it could be possible that older dogs have an increased likelihood of exposure to different filarial vectors. Moreover, despite the high percentage of mestizo dogs positive for microfilaria infection $(59 \%, 48 / 82)$, we did not find breed as a factor associated with filaria cases (Table 1). Some of these mestizo dogs had been rescued directly from the street or living in shelters. This is important considering that $A$. reconditum is transmitted by vectors such as fleas (Ctenocephalides felis) and lice (Heterodoxus spiniger) [3] that commonly infest stray or refuged dogs rather than "pure" breed dogs $[41,46]$. In fact, a study in Zambia, reported a prevalence of 7.6\% microfilariasis (different from D. immitis) in mestizo dogs and not any dog of "pure" breed with these nematodes among 272 dogs studied [47].

We observed a higher concentration of cases in the Southwest of Cali, identified as a red area in the map (Figure 4). This cluster of canine filariasis coincides with the location of the biggest dog refugee centers as well as recent informal and formal urbanization projects. This area of current development has more distribution of vegetation (compared with the other parts of the city), with small of water bodies (such as Melendez, Lili, and Pance rivers and small pounds, Figure 4 and S1). Additionally, according to the local environmental administration reports, the Southwest of Cali has a higher distribution of urban wetlands and has the lowest surface temperatures in the urban area of the city (ranging from $17.4^{\circ} \mathrm{C}-23.8^{\circ} \mathrm{C}$, Figure S1) [48, 49]. These environmental conditions may favor the growth and dissemination of different vectors for the filariae. It is necessary to explore the presence of previously known (fleas and lice) and potentially new vectors for A. reconditum in the city that could affect the geographic distribution of this filariae.

We acknowledge some limitations of our study, such as the need to expand the PCR-sequencing analysis for more samples, however, the number of sequenced strains was given by the budget restrictions. Additionally, we did not quantify the parasitemia, which could have helped to explain the reason for low sensitivity for some cases and the detection limit of the PCR test after the standardization in our lab. We propose to expand the number of subjects to include dogs from other areas of Colombia and potentially identify other filariae in order to build a diagnostic algorithm, based on the species and clinical findings identified. 


\section{Materials and Methods}

\subsection{Sample collection and study setting}

Positive canine filariasis cases detected by microscopy from August 2018 to August 2019 were selected for this prospective study. The canines were either initially diagnosed at a local veterinary center or sent from another veterinary laboratory/clinic from Cali, Colombia, or the neighboring cities. Animals owners were asked to bring the animal to enroll in the study, provide a new blood sample and, fill out an informed consent before the canines were included in the study. In parallel, samples from healthy dogs of different sex and breeds were collected as a control group.

\subsection{Variables}

A case report format (CRF) was filled out including the clinical and sociodemographic characteristics of the canines such as the canine age, breed, address during the last year, presence of ectoparasites (lice, fleas, and/or ticks) and, any noticeable clinical sign such as weakness, malnutrition or cachexia, skin lesions, bleeding, ulcers, respiratory distress, seizures, among others. Participants were identified with a code to ensure data confidentiality.

\subsection{Clinical laboratory testing}

In the initial diagnosis stage, blood smears were stained with Wright and a thick drop stained with Giemsa or Knott's test for a microscopic examination that allowed us to recruit positive cases. All cases detected by microscopy were also analyzed with a serological test that specifically detects the secreted 14KDa antigen of D. immitis [50] (Canine Heartworm Ag 2.0 Bionote, Inc, Korea). These microscopic and serological tests were also performed for the control group. Additionally, a comprehensive hemogram examination was performed for cases and controls, that included the determination of hemoglobin, hematocrit, white and red blood cell counts, using the KT3800 Vet Auto Hematology analyzer (Kindle, China). Blood cell population and morphological features were confirmed by blood smear microscopic analysis by trained personnel. Total plasmatic proteins were analyzed using a refractometer.

\subsection{Molecular tests}

\subsubsection{DNA extraction}

After the positive cases and controls were enrolled in the study, a sample of venous blood was collected with ethylenediamine tetraacetic acid (EDTA, as an anticoagulant) from both groups. The time between the initial diagnosis and the second sampling for DNA isolation was from hours up to seven days. Genomic DNA (gDNA) was extracted using $200 \mu \mathrm{l}$ of EDTA anticoagulated blood from positive cases (previously detected by microscopy) and controls, using the commercial kit (Thermo Scientific ${ }^{\mathrm{TM}}$ GeneJET ${ }^{\mathrm{TM}}$ DNA Purification Kit), following the manufacturer's instructions. DNA concentration and quality were determined using a nanodrop (Thermo Scientific NanoDrop One). DNA of three filariae species (D. immitis, A. reconditum and D. repens) donated by academic institutions from Italy and Argentina, were used as positive controls to validate our molecular tests.

\subsubsection{Polymerase Chain Reaction (PCR)}

We conducted a PCR amplification of fragments of the 5.8S-ITS2-28S ribosomal subunits of different filariae, using the pan-filarial primer pair as well as the cycling conditions reported by 
Rishniw et al., 2006 [51]. Briefly, PCR mixture contained 1,5 mM de $\mathrm{MgCl}_{2}, 0.25 \mathrm{mM}$ of dNTPs (Promega), 0,5 $\mu \mathrm{M}$ of each primer DIDR-F1 y DIDR-R1 (Macrogen), 0,05 U/ $\mu \mathrm{l}$ Taq polymerase and 1X of Taq buffer (Promega), completing a final volume of $20 \mathrm{uL}$ with ultrapure water. About $60 \mathrm{ng} / \mathrm{ul}$ of DNA was added to the mixture. After the cycling conditions, PCR products were analyzed in $1.5 \%$ agarose gels and stained with SYBR® safe.

\subsubsection{Restriction Fragment Length Polymorphisms (RFLP)}

We used the in silico predicted sequence of the PCR products for the three most reported filaria species among dogs (D. immitis, D. repens and A. reconditum), using the parasite sequences, the pan-filarial primer pair defined previously by Rishniw et al [51] and the software SnapGene ${ }^{\circledR}$ version 5.1.5. With these sequences, we identified the restriction enzyme MwoI that selectively generates two products of 285 and $288 \mathrm{bp}$ from the A. reconditum amplicon, without cutting the PCR product obtained from the other filariae species. A. reconditum was selected since the serologic test already differentiated $D$. immitis. Additionally, A. reconditum and D. immitis are the most frequently reported filariae species, autochthonous in the Americas, while $D$. repens has been mostly reported in Europe,[52] with reduced chances to be present in our region. RFLP was then performed in a final volume of $15 \mu \mathrm{l}$, which contained $1.5 \mu \mathrm{l}$ of ultrapure water, $1.2 \mu \mathrm{l}$ of enzyme buffer; $0.3 \mu \mathrm{l}$ of the enzyme and, $12 \mu \mathrm{l}$ of product from the pan-filarial PCR. The enzymatic digestion mixture was incubated at $60^{\circ} \mathrm{C}$ during 15 minutes as the manufacturer recommended. The digestion products were visualized in $1.5 \%$ agarose gels.

\subsubsection{PCR-Sequencing}

Sanger sequencing by capillary electrophoresis was performed using the 3500 Genetic Analyzer and the BigDye ${ }^{\mathrm{TM}}$ Terminator v3.1 Cycle Sequencing Kit (ThermoFisher Scientific), in order to confirm the RFLP findings. Data analysis was performed using the software BioEdit version 7.2.5, MEGA X version 10.1.7 and, the Basic Local Alignment Search Tool (BLAST) [53]. MEGA X was also used to build a neighbor-joining (NJ) phylogenetic tree.

\subsection{Georeferencing of cases}

All canine filariae cases were geocoded, consolidating all the addresses in an alphanumeric format in Microsoft Excel. Then, the coordinates were assigned using Google Maps and OpenStreetMap. We used ArcGis 10.2 software to assign the coordinates and the point of each address, consolidating a graphical output with a base map of the city and its surroundings (source Instituto Geográfico Agustín Codazzi of Colombia). Additionally, a heatmap was built by the transformation of vector files to raster, using a colored grid to represent clusters. A traffic light color scale was assigned, where red represents the higher concentration of cases.

\subsection{Statistical analysis}

Bivariate analysis was applied to evaluate the association between different categorical variables with the filaria cases compared to the control group. For continuous variables, a Shapiro Wilk normality test was performed and then, the medians between the groups were compared using either an unpaired $t$-test or Mann Whitney depending on data distribution. Statistical analysis was performed using STATA/MP 14.0 for Windows and the Graph Pad Prism software (version 8.4.2). 


\subsection{Ethical considerations}

All the procedures described in this work had the approval of the Institutional Ethics Committee for Care and Animal Use in Experimentation (CIECUAE) of the Universidad Icesi, Cali, Colombia; filed under the number 0019/2018. The animals included in the study were treated by trained personnel from the veterinary clinical laboratory, minimizing their discomfort. Canine's owners approved the participation of their pets in the study by signing the informed consent document.

\section{Conclusions}

The microscopic test combined with the "pan-filarial" PCR and the RFLP test using MwoI, allowed the detection of microfilariae species circulating in the South-western cities of Colombia. This study led us to identify $A$. reconditum as the most frequent causing species of the canine filariasis outbreak in Cali during 2018-2019. It is possible that climate change together with animal migration and commercial trades (including animal trade: pets and exotic animals), provide the conditions that allow the proliferation of vectors that transmit this nematode and other emerging infectious agents. Infection with $A$. reconditum has consequences in the canine's health with alterations in hemoglobin, hematocrit, and total plasmatic protein levels. Our study did not identify the presence of other species, however, the possibility of $D$. immitis cases in the region cannot be ruled out. Although $A$. reconditum is not a highly pathogenic species, this study highlights the importance of including it in the differential diagnosis of anemias and skin problems in canines from Colombia. At the public health level, it is necessary to alert the medical community about this canine pathogen since it has the potential to infect humans, as demonstrated in a human case of A. reconditum already reported in Australia, causing eye discomfort and irritation [28].

Supplementary Materials: The following are available online at www.mdpi.com/xxx/s1, Figure S1: Georeferentiation of Canine filariasis in Cali during 2018-2019, highlighting some environmental features such as surface temperature, rivers, and wetlands.

Author Contributions: Conceptualization, LMNR, CLV, ICG, and TG-C; methodology, LMNR, CLV, ICG, NE, AR, TG-C, APN, and BEF.; software, NE, AR, LMNR and APN; validation, LMNR, CLV and BEF; formal analysis, NE, AR, CLV, TG-C, APN, LMNR; investigation, NE, AR, CLV and LMNR.; resources, CLV, BEF, APN, and LMNR.; data curation, NE, AR, CLV, and LMNR.; writing-original draft preparation, NE and LMNR; writing-review and editing, NE, AR, TG-C, APN, CLV, ICG, BEF, LMNR.; visualization, NE, AR, TG-C, APN, CLV, ICG, BEF, LMNR; supervision, LMNR, CLV, and BEF; project administration, LMNR, BEF, and CLV.; funding acquisition, LMNR, TG-C, CLV, ICG and BEF. All authors have read and agreed to the published version of the manuscript.

Funding: We acknowledge the Dirección General de Investigaciones from Universidad Santiago de Cali that support this work under the contract $N^{\circ}$ 934-621119-435 and 934-621119-E31 and Universidad Icesi.

Acknowledgments: We thank veterinarians and clinical laboratory personnel from the Southwest Colombia that contributed with the awareness campaign regarding this parasitic disease and helped us to recruit participants for the study. We would also like to thank Doctor Domenico Otranto from the Università Degli Studi di Bari in Valenzano, Italy and Doctor Gaston Moré from the Universidad de la Plata in Argentina for the kind donation of the different filarids used as positive DNA controls. We thank Lorena Diaz, MSc from the Genomic Medicine lab of Universidad Icesi and Andrea Perea who contributed to the molecular biology work and the standardization of the protocols, as external validators for our PCR tests. Finally, we thank Annar Diagnostica Import for their donation of the serological tests for D. immitis used in this study.

Conflicts of Interest: The authors declare no conflict of interest. 


\section{References}

F. Simón et al., "Human and animal dirofilariasis: the emergence of a zoonotic mosaic," (in eng), Clin Microbiol Rev, vol. 25, no. 3, pp. 507-44, Jul 2012, doi: 10.1128/CMR.00012-12.

M. E. Sánchez Klinge, P. Calvo Robayo, and C. A. Mutis Barreto, "Dirofilaria immitis: una zoonosis presente en el mundo," Revista de Medicina Veterinaria, pp. 57-68, 2011.

P. H. Mar, I. C. Yang, G. N. Chang, and A. C. Fei, "Specific polymerase chain reaction for differential diagnosis of Dirofilaria immitis and Dipetalonema reconditum using primers derived from internal transcribed spacer region 2 (ITS2)," (in eng), Vet Parasitol, vol. 106, no. 3, pp. 243-52, Jun 2002, doi: 10.1016/s0304-4017(02)00032-8.

J. M. Ferrer Montaño, C. M. Árraga de Alvarado, M. Alvarado Morillo, and J. E. Sandoval Martínez, "Diagnosis of Canine Heartworm Disease: A comparative study between ELISA and Woo tests," vol. 12, ed: Revista Científica, FCV-LUZ, 2002, pp. 351-357.

J. R. Patel, S. Devi, J. P. Varshney, and K. M. Jadhav, "Epizootiological observations on canine microfilaremia in Gujarat state, India," (in eng), Vet World, vol. 11, no. 11, pp. 1564-1568, Nov 2018, doi: 10.14202/vetworld.2018.1564-1568.

M. S. Latrofa et al., "A multiplex PCR for the simultaneous detection of species of filarioids infesting dogs," (in eng), Acta Trop, vol. 122, no. 1, pp. 150-4, Apr 2012, doi: 10.1016/j.actatropica.2012.01.006.

N. Labarthe and J. Guerrero, "Epidemiology of heartworm: what is happening in South America and Mexico?," (in eng), Vet Parasitol, vol. 133, no. 2-3, pp. 149-56, Oct 2005, doi: 10.1016/j.vetpar.2005.04.006.

R. G. Maggi and F. Krämer, "A review on the occurrence of companion vector-borne diseases in pet animals in Latin America," (in eng), Parasit Vectors, vol. 12, no. 1, p. 145, Mar 2019, doi: 10.1186/s13071-019-3407-x.

S. C. Orozco, M. Arango, and W. Cardona, "Detección de antígenos de Dirofilaria immitis en caninos del Área Metropolitana del Valle de Aburrá," Revista Colombiana de Ciencias Pecuarias, vol. 19, pp. 280-290, 2006.

M. E. Sánchez Klinge, P. Calvo Robayo, and C. A. and Mutis Barreto, "Dirofilaria immitis: una zoonosis presente en el mundo," vol. 22, pp. 57-68doi: https://doi.org/10.19052/mv.560.

M. E. McCown, V. H. Monterroso, and W. Cardona, "Surveillance for Ehrlichia canis, Anaplasma phagocytophilum, Borrelia burgdorferi, and Dirofilaria immitis in Dogs From Three Cities in Colombia," (in eng), J Spec Oper Med, vol. 14, no. 1, pp. 86-90, 2014.

C. Vieira, M. Montoya, S. Agudelo, I. D. Velez, and F. Simón, "Human antibody response to a 56-kDa purified excretory/secretory product of Dirofilaria immitis," (in eng), Trop Med Int Health, vol. 5, no. 12, pp. 855-9, Dec 2000, doi: 10.1046/j.1365-3156.2000.00663.x. L. P. Sierra Suárez, J. T. Peláez Soto, and J. R. Ahcar Olmos, "The building sector in Cali (Colombia): An economic review to its recent evolution and major determinants," Perfil de Coyuntura Económica, pp. 119-132, 2010.

F. Simón, J. González-Miguel, A. Diosdado, P. J. Gómez, R. Morchón, and V. Kartashev, "The Complexity of Zoonotic Filariasis Episystem and Its Consequences: A Multidisciplinary View," BioMed Research International, vol. 2017, p. 6436130, 2017/05/31 2017, doi: 10.1155/2017/6436130.

D. R. Easterling and M. F. C. L. Wehner, "Is the climate warming or cooling?," Geophysical Research Letters, vol. 36, no. 8, pp. n/a-n/a, 2009, doi: 10.1029/2009GL037810. 
D. Campbell-Lendrum, L. Manga, M. Bagayoko, and J. Sommerfeld, "Climate change and vector-borne diseases: what are the implications for public health research and policy?," (in eng), Philos Trans R Soc Lond B Biol Sci, vol. 370, no. 1665, Apr 2015, doi: 10.1098/rstb.2013.0552. J. Rocklöv and R. Dubrow, "Climate change: an enduring challenge for vector-borne disease prevention and control," (in eng), Nat Immunol, vol. 21, no. 5, pp. 479-483, 05 2020, doi: 10.1038/s41590-020-0648-y.

A. D. Dobson and S. K. Auld, "Epidemiological Implications of Host Biodiversity and Vector Biology: Key Insights from Simple Models," (in eng), Am Nat, vol. 187, no. 4, pp. 405-22, Apr 2016, doi: $10.1086 / 685445$.

T. C. Orihel and M. L. Eberhard, "Zoonotic filariasis," (in eng), Clin Microbiol Rev, vol. 11, no. 2, pp. 366-81, Apr 1998.

D. Escribano et al., "Changes in serum proteins in dogs with Ehrlichia canis infection," (in eng), Microb Pathog, vol. 113, pp. 34-39, Dec 2017, doi: 10.1016/j.micpath.2017.10.024.

D. O. Avazi et al., "Evaluation of levels of interleukin-6, interleukin-8 and some haematologic parameters of dogs with cutaneous wounds," (in eng), Cytokine, vol. 113, pp. 128-138, 01 2019, doi: 10.1016/j.cyto.2018.06.024.

R. S. Nicholls et al., "Elimination of onchocerciasis from Colombia: first proof of concept of river blindness elimination in the world," (in eng), Parasit Vectors, vol. 11, no. 1, p. 237, 04 2018, doi: 10.1186/s13071-018-2821-9.

S. E. Pratt, R. M. Corwin, L. A. Selby, and J. D. Rhoades, "Prevalence of Dirofilaria immitis and Dipetalonema reconditum infections in Missouri dogs," (in eng), J Am Vet Med Assoc, vol. 179, no. 6, pp. 592-3, Sep 1981.

S. Patton and C. T. Faulkner, "Prevalence of Dirofilaria immitis and Dipetalonema reconditum infection in dogs: 805 cases (1980-1989)," (in eng), J Am Vet Med Assoc, vol. 200, no. 10, pp. 1533-4, May 1992.

E. Napoli et al., "Development of Acanthocheilonema reconditum (Spirurida, Onchocercidae) in the cat flea Ctenocephalides felis (Siphonaptera, Pulicidae)," (in eng), Parasitology, vol. 141, no. 13, pp. 1718-25, Nov 2014, doi: 10.1017/S0031182014001000.

A. Masny, T. Lewin, R. Salamatin, and E. Golab, "The first report on detection of canine Acantocheilonema reconditum in Poland and the associated diagnostic problems," (in eng), Pol J Vet Sci, vol. 14, no. 3, pp. 485-7, 2011, doi: 10.2478/v10181-011-0073-0.

A. M. Ionică et al., "Current surveys on the prevalence and distribution of Dirofilaria spp. and Acanthocheilonema reconditum infections in dogs in Romania," (in eng), Parasitol Res, vol. 114, no. 3, pp. 975-82, Mar 2015, doi: 10.1007/s00436-014-4263-4.

T. Huynh, J. Thean, and R. Maini, "Dipetalonema reconditum in the human eye," (in eng), Br J Ophthalmol, vol. 85, no. 11, pp. 1391-2, Nov 2001.

M. Hoseini, F. Jalousian, S. H. Hoseini, and A. Gerami Sadeghian, "A cross sectional study on," (in eng), Vet Res Forum, vol. 11, no. 2, pp. 185-190, 2020, doi: 10.30466/vrf.2018.78930.2046.

C. Ferreira et al., "Molecular characterization of Dirofilaria spp. circulating in Portugal," (in eng), Parasit Vectors, vol. 10, no. 1, p. 250, May 2017, doi: 10.1186/s13071-017-2180-y.

R. K. Falls and T. R. Platt, "Survey for heartworm, Dirofilaria immitis, and Dipetalonema reconditum (Nematoda:Filarioidea) in dogs from Virginia and North Carolina," (in eng), Am J Vet Res, vol. 43, no. 4, pp. 738-9, Apr 1982. 
E. G. G. de Argôlo et al., "Canine filariasis in the Amazon: Species diversity and epidemiology of these emergent and neglected zoonoses," (in eng), PLoS One, vol. 13, no. 7, p. e0200419, 2018, doi: 10.1371/journal.pone.0200419.

A. C. Brito et al., "Prevalence of canine filariasis by Dirofilaria immitis and Dipetalonema reconditum in Maceió, Alagoas State, Brazil," (in por), Cad Saude Publica, vol. 17, no. 6, pp. 1497-504, 2001 Nov-Dec 2001, doi: 10.1590/s0102-311x2001000600021.

E. Brianti et al., "New insights into the ecology and biology of Acanthocheilonema reconditum (Grassi, 1889) causing canine subcutaneous filariosis," (in eng), Parasitology, vol. 139, no. 4, pp. 530-6, Apr 2012, doi: 10.1017/S0031182011002198.

P. F. Boreham and R. B. Atwell, "Dipetalonema reconditum in dogs with microfilaraemia," (in eng), Aust Vet J, vol. 62, no. 1, pp. 27-8, Jan 1985, doi: 10.1111/j.1751-0813.1985.tb06040.x. L. C. Wang, "Canine filarial infections in north Taiwan," (in eng), Acta Trop, vol. 68, no. 1, pp. 115-20, Oct 1997, doi: 10.1016/s0001-706x(97)00081-8.

D. D. Krucik, W. Van Bonn, and S. P. Johnson, "Association between positive canine heartworm (Dirofilaria immitis) antigen results and presence of Acanthocheilonema odendhali microfilaria in california sea lions (Zalophus californianus)," (in eng), J Zoo Wildl Med, vol. 47, no. 1, pp. 25-8, Mar 2016, doi: 10.1638/2014-0116.1.

R. B. Grieve, "Immunologic relevance of the cuticle and epicuticle of larval Dirofilaria immitis and Toxocara canis," (in eng), Acta Trop, vol. 47, no. 5-6, pp. 399-402, Jul 1990, doi: 10.1016/0001-706x(90)90041-w. M. Schnyder, K. Stebler, T. J. Naucke, S. Lorentz, and P. Deplazes, "Evaluation of a rapid device for serological in-clinic diagnosis of canine angiostrongylosis," (in eng), Parasit Vectors, vol. 7, p. 72, Feb 2014, doi: 10.1186/1756-3305-7-72.

M. Schnyder and P. Deplazes, "Cross-reactions of sera from dogs infected with Angiostrongylus vasorum in commercially available Dirofilaria immitis test kits," (in eng), Parasit Vectors, vol. 5, p. 258, Nov 2012, doi: 10.1186/1756-3305-5-258.

41 P. A. Megat Abd Rani, P. J. Irwin, M. Gatne, G. T. Coleman, L. M. McInnes, and R. J. Traub, "A survey of canine filarial diseases of veterinary and public health significance in India," (in eng), Parasit Vectors, vol. 3, p. 30, Apr 2010, doi: 10.1186/1756-3305-3-30. M. Hashem and A. Badawy, "Hematological and biochemical studies on filariasis of dogs," 2007. A. K. Kannenberg, L. Frondana, I. H. R. Martins, C. E. Longhi, M. M. Fialkowski, and V. Milczewski, "Occurrence of filarid parasites in household and sheltered dogs in the city of joinville Santa Catarina, Brazil," Ciência Animal Brasileira, vol. 20, 2019.

G. Cringoli, L. Rinaldi, V. Veneziano, and G. Capelli, "A prevalence survey and risk analysis of filariosis in dogs from the Mt. Vesuvius area of southern Italy," (in eng), Vet Parasitol, vol. 102, no. 3, pp. 243-52, Dec 2001, doi: 10.1016/s0304-4017(01)00529-5.

C. Aranda, O. Panyella, R. Eritja, and J. Castellà, "Canine filariasis. Importance and transmission in the Baix Llobregat area, Barcelona (Spain)," (in eng), Vet Parasitol, vol. 77, no. 4, pp. 267-75, Jun 1998, doi: 10.1016/s0304-4017(98)00109-5.

K. Abarca, D. Gárate, J. López, and G. Acosta-Jamett, "Flea and ticks species from dogs in urban and rural areas in four districts in Chile," Archivos de medicina veterinaria, vol. 48, pp. 247-253, 2016. J. Siwila, E. T. Mwase, P. Nejsum, and P. E. Simonsen, "Filarial infections in domestic dogs in Lusaka, Zambia," (in eng), Vet Parasitol, vol. 210, no. 3-4, pp. 250-4, Jun 2015, doi: 10.1016/j.vetpar.2015.04.009. 
DAGMA, 2019. Documento técnico del inventario de humedales. Available at:

http://datos.cali.gov.co/dataset/87d2afb1-27ca-461d-858c-26257c214dc7/resource/117fd95e-fb70-4c9f-9

5f2-5d42b8b0f7a1/download/documento-tecnico-del-inventario-de-humedales.pdf. Accessed 4

October, 2020. Online.

49 "CIAT, DAGMA and CVC, 2015. Estudio para la Microzonificación Climática para el Municipio de Santiago de Cali. Available at:

http://ciat-library.ciat.cgiar.org/articulos ciat/biblioteca/ESTUDIO_PARA_LA MICROZONIFICACIO

N CLIMATICA PARA_EL MUNICIPIO DE SANTIAGO DE_CALI.pdf. Accessed 4 October, 2020."

M. Khanmohammadi et al., "Application of Dirofilaria immitis immunoreactive proteins in serodiagnosis," (in eng), Parasite Immunol, vol. 41, no. 1, p. e12598, 01 2019, doi: 10.1111/pim.12598.

M. Rishniw, S. C. Barr, K. W. Simpson, M. F. Frongillo, M. Franz, and J. L. Dominguez Alpizar,

"Discrimination between six species of canine microfilariae by a single polymerase chain reaction," (in eng), Vet Parasitol, vol. 135, no. 3-4, pp. 303-14, Feb 2006, doi: 10.1016/j.vetpar.2005.10.013.

S. Little, M. Saleh, M. Wohltjen, and Y. Nagamori, "Prime detection of Dirofilaria immitis:

understanding the influence of blocked antigen on heartworm test performance," (in eng), Parasit Vectors, vol. 11, no. 1, p. 186, 03 2018, doi: 10.1186/s13071-018-2736-5.

S. Kumar, G. Stecher, M. Li, C. Knyaz, and K. Tamura, "MEGA X: Molecular Evolutionary Genetics Analysis across Computing Platforms," (in eng), Mol Biol Evol, vol. 35, no. 6, pp. 1547-1549, 06 2018, doi: 10.1093/molbev/msy096. 